Tohoku J. exp. Med., 1964, 83 114-120

\title{
Plaque Formation and Growth Characteristics of Sendai Virus in Chick Kidney Cell Cultures
}

\author{
By \\ Shirô Shigeta \\ Department of Pediatrics; Director: Prof. Ts. A r a k a w a and \\ Department of Bacteriology; Director: Prof. N. I s hid a \\ Tohoku University School of Medicine, Sendai
}

(Received for publication, March 24, 1964)

\begin{abstract}
Sendai virus (Parainfluenza virus type I) formed the plaques on monolayer culture of kidney cells of 2 or 3 day old chicks. A linear relationship between the concentration of virus and the number of plaque was observed.

Plaque forming unit of Sendai virus with chick kidney monolayers was about one-third to one-tenth of that of $50 \%$ egg infectious doses. Growth of Sendai virus in chick kidney cell monolayer reached a maximum titer at 15 hours and production of infectious particles by single cell was calculated at about 25 plaque forming units.
\end{abstract}

During the course of studies on Sendai virus, a plaque counting method was necessitated for the precise determination of infectious titers. Since primary cultures of chick kidney cells have been reported ${ }^{1-3}$ ) to allow the growth of many viruses including the viruses of influenza and parainfluenza, the availability of this cell culture for the growth of Sendai virus was examined in this laboratory. When high virus input was added to the monolayer cultures of the cell, marked cytopathic effects were observed and hemagglutinins in the culture fluid reached a maximum within 3 days. While with low virus input, the cytopathic effects were first observed on the 5th day, and hemagglutinins in the culture fluid increased gradually to a maximum titer, comparable to that of high virus input by the 9th day. This observation suggested the multiple-step growth of Sendai virus in chick kidney cell culture that was never observed in either HeLa or L cells ${ }^{4,5}$. Thus when the virus titer of infected allantoic fluid was determined in these cell cultures, the infectious titer was almost comparable to that determined in eggs, suggesting the high sensitivity of the cell culture to Sendai virus. These preliminary studies prompted the experiments on the establishment of plaque counting procedure by using the chick kidney cells.

茂田士郎 


\section{MATERIALS AND METHODS}

Tissue culture of chick kidney cells: Kidneys obtained from 2 or 3 day-old chicks were washed once with Hanks' balanced salt solution (BSS) for 15 minutes by stirring with a magnetic stirrer, and then digested with $0.1 \%$ trypsin in the $\mathrm{Ca}^{++}$and $\mathrm{Mg}^{++}$free-phosphate buffered saline of $\mathrm{pH} 7.2$ by stirring for 10 minutes at $27^{\circ} \mathrm{C}$. The trypsinization was repeated five times. The first and the second cell-suspensions were discarded to remove the red blood cells. The third, fourth and fifth cell-suspensions were combined and served for the cell culture.

The growth medium used consisted of $0.5 \%$ lactalbumin hydrolysate and $10 \%$ calf serum in Hanks' BSS. Five milliliters of cell suspensions containing $6 \times 10^{5}$ cells/ml, in the growth medium, was inoculated into two-ounce bottles and cultivated at $37^{\circ} \mathrm{C}$. The cells were ready for use on the third day. For maintenance purpose, MS medium $(0.5 \%$ lactalbumin hydrolysate, $0.1 \%$ yeast extract, and $2 \%$ inactivated horse serum in Earle's BSS) was used.

Virus: Fushimi strain of Sendai virus which had been numerously passaged in chick embryos was used throughout the study. The viral materials for the inoculation of the cell cultures were allantoic fluid of chick embryos, which was prepared by infection with $0.2 \mathrm{ml}$ of $10^{-6}$ diluted stock virus and harvested after incubation for 48 hours at $37^{\circ} \mathrm{C}$.

Plaque assay procedure: The growth medium was removed from the monolayer cultures of the cells grown for 3 days. The cells were washed twice with the MS medium and inoculated with $0.2 \mathrm{ml}$ of appropriate dilutions of virus in MS medium. After the adsorption period of 1 hour at $37^{\circ} \mathrm{C}, 3.5 \mathrm{ml}$ of primary agar overlay medium was added to the culture bottles without washing the cell sheet. When the agar had solidified, the bottles were incubated at $37^{\circ} \mathrm{C}$. The agar overlay medium consisted of $1.0 \%$ Bact agar (Difco), $0.5 \%$ lactalbumin hydrolysate, $0.1 \%$ yeast extract, $0.2 \%$ sodium bicarbonate and $10 \%$ unheated bovine serum in a base of Earle's BSS. Following 3 days of incubation, the bottles were overlaid again with $2.5 \mathrm{ml}$ of the overlay medium containing 1: 10,000 neutral red. Plaque forming unit (PFU) was finally determined after 8 days following the virus inoculation.

Infectivity titration of virus in eggs: Infectivity of virus for eggs was determined by using 4 to 6 ten-day-old embryonated eggs for each 10-fold dilution of the virus and $\mathrm{EID}_{50}(50 \%$ egg infectious dose) was calculated by the Reed and Muench's method.

\section{EXPERIMENTAL RESULTS}

The plaques formation and the effect of medium composition

Plaques were first visible on the 4th day of incubation as opaque dots from $0.5 \mathrm{~mm}$ to $1.0 \mathrm{~mm}$ in diameter with exposure to oblique light. Daily count indicated that the number increased gradually and reached a maximum by the 8 th 
day. Most of the plaques measured from 1.0 to $4.0 \mathrm{~mm}$ in diameter. The plaques were varied in size and had rather irregular edges (Fig. 1),

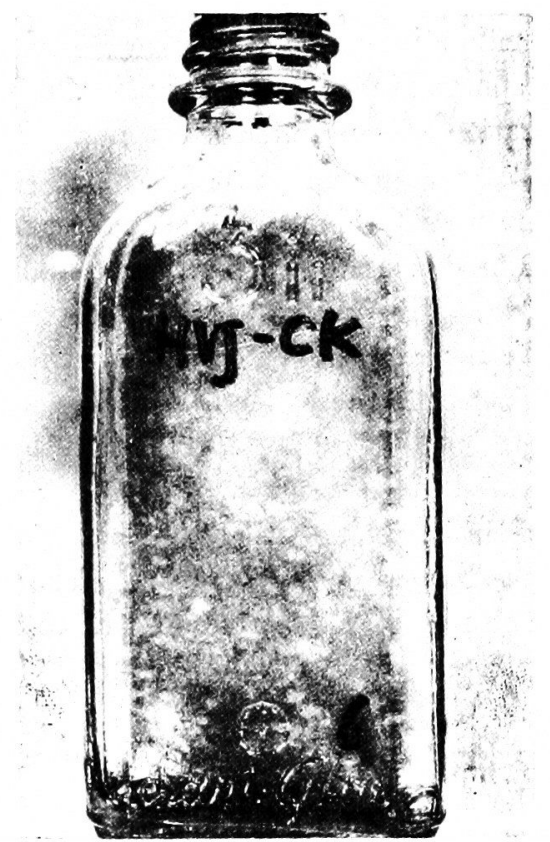

Fig. 1. Plaques of Sendai virus in chick kidney cell culture 10 days after seeding.

Attempts were made to increase the number and size of the plaques. The use of an agar overlay medium, containing $10 \%$ bovine serum, resulted in an increase in the size and number of plaques as compared to that containing the same concentration of horse serum. Heating of the bovine serum at $56^{\circ} \mathrm{C}$ for 30 minutes, did not affect the plaque size nor plaque numbers. Increasing the concentration of bicarbonate in the medium from $0.1 \%$ to $0.2 \%$ resulted the formation of enlarged plaques, and that the plaques became to be more easily read because viable cells showed more intense red color. No inhibitory effect on Sendai virus growth was observed with all of the bovine sera used for the overlay medium, by using the ordinary neutralization test in chick embryos.

\section{The effect of adsorption period on plaque numbers}

A series of 3-day-old monolayers, in 2-ounce bottles, were once washed with MS medium and inoculated with $0.2 \mathrm{ml}$ of egg-grown Sendai virus diluted in the MS to give approximately 120 plaques per bottle. At adequate intervals, shown in Table I, Bottles were washed three times with $5 \mathrm{ml}$ of MS medium and overlayed as described above. The remainder of the procedures followed is as described above. 
The results shown in Table I, illustrate that differences cannot be found between the adsorption period of 40 and 60 minutes. Therefore, virus adsorption for 60 minutes was selected for the plaque assay.

Relation between virus concentration and number of plaques

The relationship of virus dilution to plaque number was also examined. Starting at $10^{-6}$ stock virus concentration, two-fold dilutions were made in MS medium, and resulted plaque numbers were compared. A linear relationship was observed between the virus concentration and the number of plaques, indicating that each plaque was produced by a single infectious unit, as shown in Fig. 2.

Comparison of $P F U$ and $E I D_{50}$

Six allantoic fluid harvests were examined for their infectious titer both by the plaque assay in the chick kidney cell culture and the inoculation to embryonated

TABLE I. Adsorption of Sendai Virus onto Chick Kidney Cells after Different Lengths of Time

\begin{tabular}{c|c|c}
\hline Adsorption time & PFU*/bottle & $\%$ of maximum \\
\hline 10 minutes & 68 & 56 \\
$20 "$ & 110 & 94 \\
$40 "$ & 118 & 100 \\
$60 "$ & 118 & 100
\end{tabular}

* plaque forming unit.

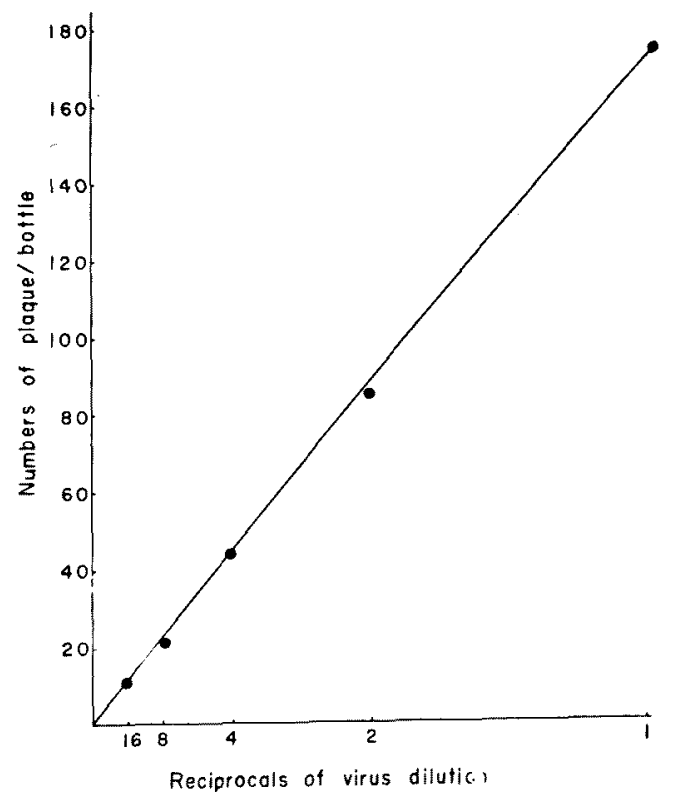

Fig. 2. Relation between plaque counts and serial dilution of Sendai virus. 
TaBle II. Comparison of Titers of Sendai Virus Grown on Several Host Cells by Egg and Chick Kidney Titrations

\begin{tabular}{|c|c|c|c|c|c|}
\hline & Virus source* & Passage No. & $\underset{(\log )}{\mathrm{HAU} / \mathrm{ml}}$ & $\underset{(\log )}{\operatorname{EID}_{50} / m \mathrm{ml}}$ & $\underset{(\mathrm{log})}{\mathrm{PFU} / \mathrm{ml}}$ \\
\hline 1 & Egg & 77 & 4.0 & 10.4 & 9.4 \\
\hline 2 & $" \prime$ & 78 & 3.9 & 10.2 & 9.2 \\
\hline 3 & $"$ & 79 & 3.6 & 10.2 & 9.3 \\
\hline 4 & $" \prime$ & 81 & 4.0 & 10.0 & 9.4 \\
\hline 5 & $"$ & 82 & 3.9 & 10.2 & 9.4 \\
\hline 6 & $"$ & 83 & 3. 6 & 10.1 & 9.6 \\
\hline 7 & MK & 1 & 2.6 & 7.5 & 6.2 \\
\hline 8 & " & 4 & 2.6 & 8.1 & 6.8 \\
\hline 9 & CK & 1 & 2.8 & 7.0 & 6.4 \\
\hline 10 & $" \prime$ & 8 & 2.0 & 7.1 & 7.3 \\
\hline 11 & $\mathbf{L}$ & 1 & 2.0 & 6.0 & $<2.5$ \\
\hline 12 & $"$ & 1 & 2.3 & 7.1 & 3.6 \\
\hline 13 & Mouse & 1 & 1.9 & 7.0 & 6.0 \\
\hline 14 & $"$ & 3 & $<1.0$ & 4.7 & 4.8 \\
\hline
\end{tabular}

* Egg: Allantoic fluids of embryonated eggs.

MK: Cynomolgus monkey kidney culture.

CK: Chick kidney cell culture.

L: $L$ cell culture.

Mouse: Mouse lung suspension infected intranasally.

eggs.

The result in Table II shows that the PFU was equivalent to one-third to onetenth of $\mathrm{EID}_{50}$. On the other hand, when a few stock viruses propagated in either chick kindey cell culture or mouse lung were tested, PFU was almost comparable to the $\mathrm{EID}_{50}$ with same stocks (Table II). However, this was not the case with monkey kindey cell- or L cell-grown viruses. Further studies with this particular respect will be reported elsewhere. It was noted in the several experiments that the PFU was almost comparable or higher than titer of endpoint dilution unit in chick kidney cell culture.

Growth characteristics of virus in monolayer culture of chick kidney cells

In order to observe the growth characteristics of Sendai virus, tube cultures containing $2 \times 10^{6}$ cells were inoculated with $1.0 \mathrm{ml}$ of virus containing $10^{7.4}$ $\mathrm{PFU} / \mathrm{ml}$. After incubation for 1 hour at $37^{\circ} \mathrm{C}$, the monolayers were washed twice with $2 \mathrm{ml}$ of MS medium. Then $1 \mathrm{ml}$ of fresh MS medium was added, and the incubation was continued.

At intervals, as indicated in Fig. 3, five tubes were taken and were frozen and thawed five times. The suspensions were pooled and centrifuged at 3,000 rpm for 5 minutes and the supernatant fluids were stored at $-20^{\circ} \mathrm{C}$ until tested by plaque technique.

Following a latent period of 5 hours, the amount of virus, began to increase exponentially, as shown in Fig. 3. Seven hours later, first detectable morphological changes of infected cells were noticed and almost all of the cells turned to 


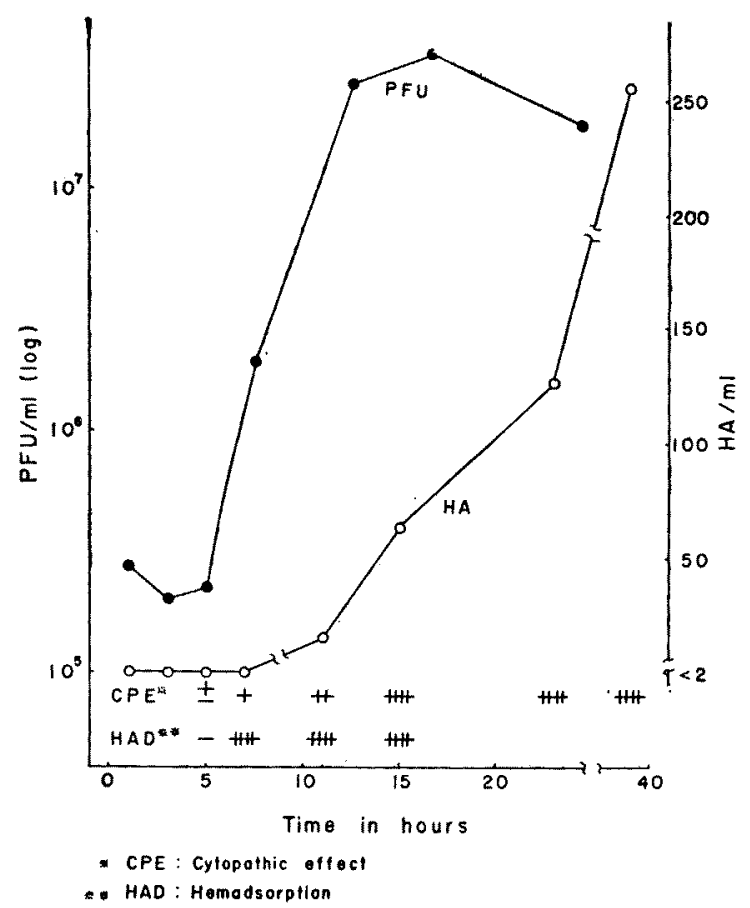

Fig. 3. Growth curve of Sendai virus on chick kidney cell monolayer.

adsorb chicken red blood cells uniformly on their surface.

Particular changes of cells extending the protrusions were noticed, and the production of hemagglutinins was first detected, 11 hours later. The amount of virus reached a maximum at 15 hours. Now, the cells seem to be round and swollen, and granulations in cytoplasm appeared. The amount of hemagglutinins continued to increase up to 40 hours. The amount of virus produced by single cell in such a cultural conditions, was calculated to be an average of 25 PFU.

\section{DISCUSSION}

Recently Hsiung et al. $\left.{ }^{6}\right)$ have reported the isolation of a myxovirus, the DA virus with plaque technique. It has been difficult to make plaques of myxovirus among others. Therefore, some methods using plasma clot?) or liquid ${ }^{8}$ fluid instead of agar were reported, but these methods required complicated techniques and were not suitable for the accurate assays than conventional agar overlay method. In this work, agar overlay method was employed, using a simple technique for the plaque formation of Sendai virus.

In order to increase the number and size of plaques, composition of overlay medium was examined as follow, unless otherwise stated in the text. Chickembryo extract was added according to the report by Dulbeceo ${ }^{9}$ and by Frothing- 
ham $^{10)}$. Medium 199 was used following the plaque formation of hemadsorption virus type 1 which is also classified as parainfluenza as Sendai virus ${ }^{11)}$. After the model of plaque formation of adenovirus ${ }^{12)}$, certain amino acids in high concentrations were added to medium. However, all of these attempts did not effect the numbers and the size of plaque.

On the basis of the fact that plaque size was sometimes varied in different culture of chick kidney cell, virus growth may be affected by conditions of cell culture, namely trypsinization of kidney, amount of inoculum of suspended cells and growth rate of cell layer. Quantity of agar overlay medium and neutral red were also examined. Increase of the overlay medium in volume did not improve the plaque formation. The neutral red in agar overlay was destructive for the cell sheet, and the cell sheet was stained with second agar overlay and incubated in the dark to prevent the photodynamic effects on cell culture $^{13-15)}$.

\section{Acknowledgment}

The author is indebted to Prof. Ts. Arakawa and Prof. N. Ishida for their guidance throughout the course of this work. He is also indebted to Assistant Prof. Y. Hinuma and Dr. M. Homma for their advice and encouragement.

\section{References}

1) Buthala, D.A. \& Mathaws, J., Cornell Vet., 1957, 47, 143.

2) Wright, B.S. \& Sagik, B.P., Virology, 1958, 5, 573.

3) Maassab, H.F., Proc. nat. Acad. Sci., 1959, 45, 1035.

4) Ishida, N. \& Homma, M., Tohoku J. exp. Med., 1960, 73, 56.

5) Ishida, N. \& Homma, M., Virology, 1961, 14, 486.

6) Hsiung, G.D., Issacson, P. \& McCollum, R.W., J. Immunol., 1962, 88, 284.

7) Ledinco, N., Nature, 1955, 175, 999.

8) Hotchin, J.E., Deibel, R. \& Benson, L.M., Virology, 1960, 10, 275.

9) Dulbecco, R., Proc, nat. Acad. Sci., 1952, 38, 747.

10) Frothingham, T.E. \& Granoff, A., Virology, 1961, 15, 213.

11) Deibel, R., ibid., 1959, 8, 262.

12) Bonifas, V. \& Schlesinger, R.W., Red. Proc., 1959, 18, 560.

13) Darnell, J.E. Jr., Lochhart, R. Z. Jr. \& Sawyer, T.K., Virology, 1958, 6, 567.

14) Klein, S.W. \& Goodgal, S.H., Science, 1959, 130, 629.

15) Green, R.H. \& Opton, E.M., Proc. Soc. exp. Biol., 1959, 102, 519. 